\title{
Information and Communication Technologies as the Means of Forming Research Competence Future Teachers
}

\author{
Sergey Kravchenko ${ }^{1} *$ [0000-0001-9008-8816], Vitaliia Harapko 2 [0000-0001-7171-8448] \\ ${ }^{1}$ Dnieper Vocational College of Engineering and Pedagogy of UDKHTU, Kamyanske, Ukraine \\ ${ }^{2}$ Mukachevo State University Mukachevo, Mukachevo, Ukraine \\ *kravchenko_ikollege@ukr.net
}

\begin{abstract}
Professional training of future teachers is based on the formation of their certain competencies. Successful studying activities, design, and implementation of certain educational projects hinge on the availability of research competence, the formation of individual components of which depends on the occurrence of scientifically sound and agreed on goals and content of teaching methods and tools. The use of information and communication technologies as a means of studying has become a natural response to the scientific and technological development of mankind. The relevance of their use in the educational process has been established by many studies. Some aspects of the application of information and communication technologies in the field of education have been studied by Ukrainian and foreign scientists. The study of the influence of information and communication technologies as a means of forming the research competence of future teachers was tested in the educational process of some Ukrainian higher educational establishments through the introduction of experimental methods. Their significant influence on the formation of research competence has been established. The use of information and communication technologies in the educational process allowed to increase motivation to study, to organize the independent cognitive activity of students, to create a favorable educational environment for their research activities, to encourage research work.
\end{abstract}

Keywords. Information and communication technologies, research competence, teaching aids, future teachers, educational process, teaching methods.

\section{INTRODUCTION}

In response to today's demands, a modern specialist in the field of education must acquire a certain list of competencies that must be formed during training in an educational institution. Successful solutions by future teachers of certain practical situations, the implementation of individual educational projects will depend on the formation of their research competence, the manifestation of which will successfully implement the mastered knowledge, skills, and abilities.

It is believed that the acquisition of a high level of research competence by future teachers is fully consistent with European trends in education and the reorientation of the Ukrainian system of education to the result. The emergence of new scientifically sound and consistent in terms of goals and content of teaching methods based on the use of information and communication technologies - is a natural result for the development of mankind in general.

The effectiveness of various innovative teaching methods which are based on the use of information and communication technologies, their impact on the formation of certain qualities of students in comparison with traditional, established methods, is required by extensive research. This has been especially relevant in the situation of a global pandemic, when different forms of distance learning have been actively used in the educational process, based on the use of various forms and methods of information and communication technologies.

\section{RESEARCH METHODOLOGY}

The methodological basis for the organization of analysis on the formation of research competence of 
future teachers using information and communication technologies is been such theories and concepts :

- society needs highly qualified teachers with a sufficient level of research competence;

- the need to introduce the modern methods of forming research competence during the professional training of future teachers in the school;

- the use of information and communication technologies as a means of forming research competence can exert a certain influence on the process of its formation;

- the possibility of increasing the efficiency of the process of formation of research competence of future teachers using information and communication technologies in comparison with the traditional, established system of organization of this process in the educational institutions.

Psychological and pedagogical aspects of the use of information technology in the educational process have been the subject of research by Ukrainian $[1 ; 2 ; 3 ; 4]$ and foreign scientists $[5 ; 6 ; 7 ; 8 ; 9 ; 10]$, who proved that information and communication technologies can increase the activity of cognitive activities of students, increase the number of independent forms of education. It is emphasized the importance of a detailed study of their role, possibilities, and scope in education.

These scientific works have been noted that the use of information and communication technologies can make significant changes in the system of independent work of students and more effectively achieve studying goals through visualization, rapid search for information based on free access to information sources, quickly process large amounts of information, facilitate control, evaluation and correction by the teacher and the student.

\section{RESEARCH RESULTS}

Testing of our beliefs in the effectiveness of information and communication technologies as a means of forming research competence was conducted during 2016-2018. The research involved 20 teachers and 406 students of pedagogical educational institutions. Selected respondents were divided into experimental and control groups. The control group included 202 respondents, the experimental - 204 respondents. Representativeness of the selection is allowed to obtain reliable results.

The level of formation of research competence of future teachers (creative, reconstructive, reproductive) was calculated for each respondent at the beginning and end of the study using the appropriate integrated indicator, which contains 14 indicators of the formation of research competence [11]. Its application allowed to record the initial state of the level of formation of research competence of each student and to trace the dynamics of its change during the experiment. Data for calculations were obtained through questionnaires and observation of educational activities of students involved in the study.

The obtained digital data was processed mathematically using the Microsoft Excel software package. Pearson's chi-squared test $\left(\chi^{2}\right)$ was used for statistical analysis of the research results, the level of statistical significance was $\alpha=0.05(1-\alpha=0.95)$.

The method used in the study to calculate the current level of formation of research competence of future teachers from the control and experimental groups at the beginning of the experiment allowed to obtain the following results, shown in table 1.

Table 1. Distribution of students in control (CG) and experimental (EG) groups according to the levels of formation of research competence, persons

\begin{tabular}{|c|c|c|c|c|}
\hline \multirow[b]{2}{*}{ The level of formation of research competence } & \multicolumn{2}{|c|}{ CG } & \multicolumn{2}{|c|}{ EG } \\
\hline & persons & $\%$ & $\begin{array}{c}\text { person } \\
\mathbf{s}\end{array}$ & $\%$ \\
\hline Creative & 2 & 0,99 & 2 & 0,98 \\
\hline Reconstructive & 64 & 31,68 & 62 & 30,39 \\
\hline Reproductive & 136 & 67,33 & 140 & 68,63 \\
\hline Total & 202 & 100 & 204 & 100 \\
\hline
\end{tabular}

The generalized results of this table show that there is no fundamental difference between the level of formation of research competence of students in experimental and control groups at the beginning of the study. The obtained results are shown in Figure 1.

A detailed analysis of Table 1 shows that the 
creative level of formation at the beginning of the study had approximately $1 \%$ of students in the entire sample. In turn, almost $31 \%$ was the part of persons whose level of research competence was defined as reconstructive. It should be noted that the most significant was the share of respondents with a reproductive (low) level of research competence - about $68 \%$, the rate of which is more than $2 / 3$ of the total number of respondents. The above data indicate the urgency of the need to develop and implement innovative methods using information and communicative technologies that can improve the state of the phenomenon under consideration.

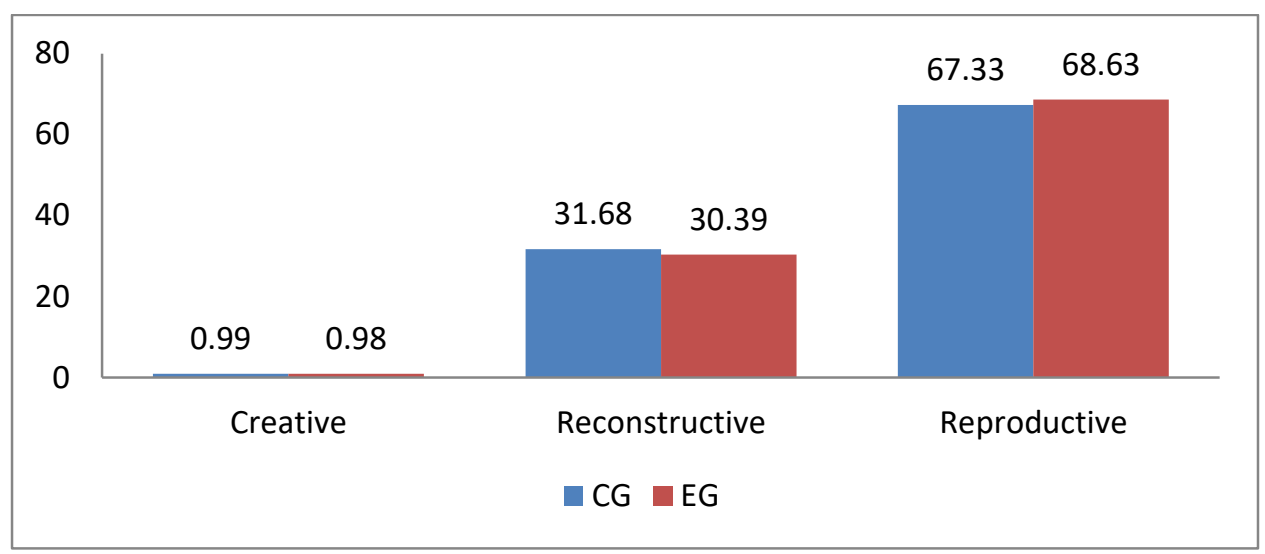

Figure 1 Distribution of future teachers of control (CG) and experimental (EG) groups according to the levels of formation of research competence $(\%)$

This conclusion is based on the results of statistical verification of the level of research competence of future teachers in experimental and control groups, using Pearson's criterion $\chi^{2}$ (chi-square), which allowed stating the random nature of differences in the results of testing the competence of research competence between control and experimental groups.

Our further research was to determine the effectiveness of the use of information and communication technologies as a means, their ability to increase the level of formation of research competence of future teachers in the process of their professional training.
At the end of the experiment, it was noted significant changes in the levels of formation of the research competency of the respondents of the experimental group. In particular, increased the share of students who demonstrated creative and reconstructive (high and medium, respectively) levels of formation of components of research competence, and vice versa the rate of students with the reproductive (low) level of research competence was decreased.

The results of the study of the impact of information and communication technologies as a means of forming the research competence of future teachers at the beginning and end of the formative experiment are shown in table 2 .

Table 2. Distribution of students of experimental (EG) and control groups (CG) by levels of formation of components of research competence $(\%)$

\begin{tabular}{|c|c|c|c|c|}
\hline \multirow{2}{*}{$\begin{array}{l}\text { Grou } \\
\text { ps }\end{array}$} & \multirow{2}{*}{ Measurements } & \multicolumn{3}{|c|}{ The level of formation of research competence } \\
\hline & & Creative & Reconstructive & Reproductive \\
\hline \multirow{3}{*}{ ভ } & Before the experiment & 0,99 & 31,68 & 67,33 \\
\hline & $\begin{array}{l}\text { At the end of the } \\
\text { experiment }\end{array}$ & 0,99 & 35,15 & 63,86 \\
\hline & Changes & 0,00 & 3,47 & $-3,47$ \\
\hline \multirow{3}{*}{ 只 } & Before the experiment & 0,98 & 30,39 & 68,63 \\
\hline & $\begin{array}{l}\text { At the end of the } \\
\text { experiment }\end{array}$ & 2,94 & 40,69 & 56,37 \\
\hline & Changes & 1,96 & 10,30 & $-12,26$ \\
\hline
\end{tabular}


It should be noted that at the end of the experiment significantly increased the rate of students in the experimental array with sufficient and high levels of research competence: an increase of $10.30 \%$ (at the reconstructive level) and $1.96 \%$ (creative), respectively. The reconstructive level was $3.47 \%$ and was not changed at the creative level.

Changes in the levels of formation of research competence of future teachers belonging to the control and experimental groups at the beginning and end of the experiment are illustrated in Figure 2.

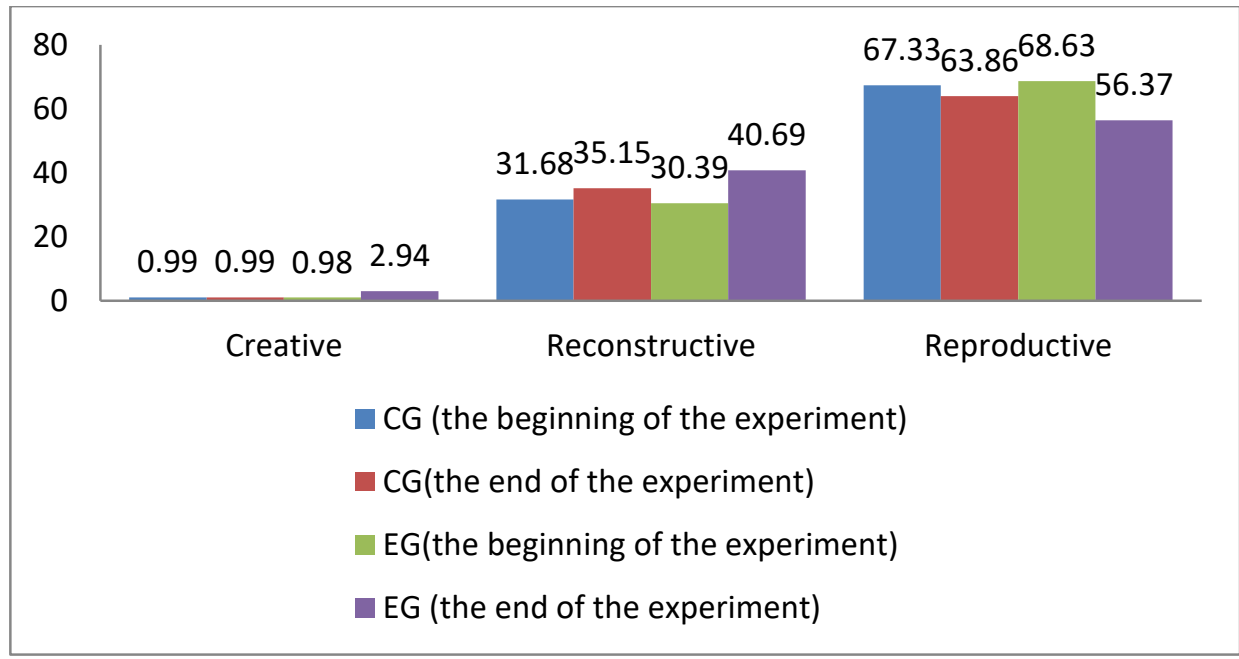

Figure 2 Increasing the levels of formation of students of experimental (EG) and control (CG) groups by levels of formation of components of research competence before and after the experiment

It should be noted that in the control groups there are also some changes, but not so significant: the rate of people with a reconstructive level was increased by about $3.5 \%$ and the rate of people with a reproductive level of research competence was decreased by $3.5 \%$.

Analysis of the distribution of students in the experimental groups which were involved in the study suggests that there was a significant decrease in the number of students with a reproductive level of formation of research competence.

From the given data it is seen that the use of information and communication technologies in teaching and research activities as a means of forming research competence of future teachers at the end of the experiment in experimental groups were lead to significant changes in the levels of research competence.

It is worth noting that at the end of the experiment, students of experimental groups more actively, confidently, and with a higher level of motivation participated in the research, attended conferences, scientific seminars, round tables compared to students in the control group, communicated and consulted on scientific issues with teachers and scientists. At the end of the experiment it was stated: almost every student reported the results of their scientific work at meetings (conferences) of different levels, most of them participated in the publication of printed works, both individual and collective in the form of scientific articles or abstracts of scientific conferences.

\section{RESULTS AND DISCUSSION}

The results of the assessment of the formation of research competence, calculated by the integrated indicator, suggest the inadequate attention in the modern education process of teacher training to the means of information and communication technologies, which should be paid more special attention in the future.

The objectivity and reliability of the experimental data were ensured under the following conditions:

- in the study groups there were students of I-IV courses, who studied according to unified curricula and programs;

- control and experimental groups were formed in each institution of higher education in pairs, and therefore the effect of random factors in the control and experimental groups was stated approximately the same;

- the sample size was representative (number of students in the control groups: at the beginning of the experiment - 202 people at the end - 202 people; the number of students in the experimental groups: at the beginning of the experiment - 204 people, at the end 204 people).

Experimentally, it was confirmed the correctness of our conceptual statement that the involvement of information and communication technologies can ensure the effective formation of research competence 
of future teachers. The use of information and communication technologies in the educational process allowed to increase self-confidence and enlarge motivation to study disciplines, more effectively organize the independent cognitive activity of students, create a favorable educational environment for their research activities, encourage them to carry out research (participation in conferences, scientific circles, and schools, implementation research projects).

\section{CONCLUSIONS}

According to the results of our study, the awareness of students and teachers about the possibilities of different usage of information and communication technologies in the educational process has increased. It has been expanded the scope of their application as a means of teaching and the formation of individual competencies of students. There are some forms and methods of information and communication technologies, which are appropriate for organizing theoretical, practical, and independent work with students. Among them, there is used the Google services, Intel-projects, multimedia presentations, interactive whiteboards, educational forums, educational databases, virtual libraries, VR-Headsets, and for designing electronic portfolios, educational libraries, e-comics, doodles, word clouds, web quests, tasks with QR-codes, QR-quests, thematical blogging, virtual tours, etc. [12].

Further research on this issue is seen in determining the critical limits of the impact of information and communication technologies as a means of studying and the formation of individual competencies of future pedagogues.

\section{REFERENCES}

[1] Shyshkina, M.P. Spirin, O.M. and Zaporozhchenko, Y.G. (2012), "Problems of informatization of education in ukraine in the context of development of research of ict-based tools quality estimation", Information Technologies and Learning Tools, vol. 27 (1). DOI: https://doi.org/10.33407/itlt.v27i1.632.

[2] Danylyuk, S.S. (2013), "Philosophical basics of formation of future philologists' professional competence by means of internet technologies", Information Technologies and Learning Tools, vol. 33 (1). DOI: https://doi.org/10.33407/itlt.v33i1.783

[3] Stavytskyi, O. and Urazgaliyeva, M. (2018), "Using google classroom tools in teaching students of economic specialities", AdvancedEducation, [S.1.], pp. 76-81. DOI: http://dx.doi.org/10.20535/2410-8286.149361.
[4] Kulish, A. Radul, V. Haleta, Y. Filonenko, O. and Karikh, I. (2020), "The Newest Digital Technologies in Education and the Prospects of Their Implementation in Ukraine", Propósitos y Representaciones, no. $8 . \quad$ DOI http://dx.doi.org/10.20511/pyr2020.v8nSPE2.68 4

[5] Wei Li, Ruijin Zhou, PeiqiDeng, Qiang Fang and Pengwei Zhang (2012), "Construction of Case Teaching Model for Management Specialty Supported by Information Technology", IJEME, vol. 2, no. 9, pp. 44-48.

[6] Nader Mohamed, Jameela Al-Jaroodi and Imad Jawhar (2012), "Enhancing the Project-Based Learning Experience Through the Use of Live Web Data", IJMECS, vol. 4, no. 11, pp. 33-43.

[7] Elizaphan M. Maina, Robert O. Oboko and Peter W. Waiganjo (2017), "Using Machine Learning Techniques to Support Group Formation in an Online Collaborative Learning Environment", International Journal of Intelligent Systems and Applications, vol. 9, no. 3, pp. 26-33. DOI: 10.5815/ijisa.2017.03.04

[8] Zhang Mei (2012), "Computer Technology in Psychological Experiment Teaching”, IJEME, vol. 2, no. 2, pp. 66-73.

[9] Yixun Shi (2011), "Problem Solving, Computer Technology, and Students' Motivation in Learning Mathematics", IJEME, vol. 1, no. 1, pp. 1-5.

[10] Oluwole O. Oyetoke (2016), “Leveraging Information Technology in Automating School Management and Student Activities by Successfully Integrating a Java- based School Management Application Software", International Journal of Information Technology and Computer Science, vol. 8, no. 1, pp. 22-32. DOI: $10.5815 / \mathrm{ijitcs} .2016 .01 .03$.

[11] Kravchenko, S. (2018), "Integral indicator of level differentiation of research competence formation level of future ecologists", EUREKA: Social and Humanities, [S.1.], no. 5, pp. 29-35. DOI: http://dx.doi.org/10.21303/25045571.2018.00733

[12] Harapko, V. (2018), "Methods of using qr-codes in the practical training of foreign languages teachers in the formation of methodical and information competencies of pupils?" Professional Education: Methodology, Theory and Technologies, no. (7(1), pp. 25-35. 